Brodie, J. \& Green, D. M. (1951). J. gen. Microbiol. 5, 1001-1009.

\title{
A Study of Shigella flexneri, Sh. boydii and Sh. sonnei by Precipitation and Agglutination Reactions
}

\author{
By J. BRODIE AND D. M. GREEN \\ Department of Bacteriology, University of St Andrezos, Dundee
}

SUMMARY : Antisera, prepared against 'smooth' variants of the Flexner, Boyd and Sonne types of Shigella, were investigated for their agglutinin and precipitin content. The precipitation reactions, employing formamide extracts of the organisms, showed a marked degree of specificity which was lacking in the agglutination reactions except with the Boyd and Sonne types. Cross-precipitation reactions occurred with Boyd's Flexner IV (103) and Flexner Y and also with Boyd's Flexner V (P119) and Flexner X. Absorption tests, however, revealed each of these four organisms to have a predominant specific precipitinogen.

In previous investigations of the dysentery and colon-typhoid groups (Brodie, 1942, 1948; Brodie \& Shepherd, 1949, 1950) it was necessary to check the rough and smooth variants of the organisms employed by colony character, salt-agglutinability, and serological tests. The formamide extract of the smooth variant of Sh. sonnei gave a positive precipitation reaction with its homologous antiserum but not with the antiserum to the rough variant; a similar extract of the rough variant reacted with neither. It was decided to investigate the Flexner types of dysentery bacilli for precipitinogens both in the rough and smooth phases.

While this investigation was in process, Gonzales \& Morales-Otero (1947) published a paper on the antigenic studies of the Shigella by the precipitation reaction. On comparing our available results with theirs we found that ours showed a greater specificity and enlarged the field to include the Boyd types.

\section{METHODS}

Preparation of cultures. Smooth variants of the organisms were got by growing cultures on bile-salt citrate rosolic acid agar (Brodie, 1942). Recent batches of sodium tauroglycocholate (British Drug Houses Ltd.) have proved unsatisfactory, and in the preparation of the MacConkey's agar and the bile-salt citrate rosolic acid agar (c.R.A.), 'Bile Salts' (Oxo Ltd.) has been substituted with adequate results.

Rough variants were selected from the smooth strains by repeated subculture on ox-heart extract agar or on MacConkey's agar (1908).

Bacterial suspensions for agglutination tests. The organisms were grown for $24 \mathrm{hr}$. at $37^{\circ}$ on C.R.A., then suspended in $0.25 \%(\mathrm{v} / \mathrm{v})$ formalin in $0.85 \%$ $(\mathrm{w} / \mathrm{v})$ saline. Further dilution in physiological saline to $2 \times 10^{9}$ organisms $/ \mathrm{ml}$. (Brown's scale) was used for all agglutination tests.

Preparation of antisera. The organisms were grown for $24 \mathrm{hr}$. at $37^{\circ}$ on c.R.A., and suspended in physiological saline to give a concentration of $2 \times 10^{9} / \mathrm{ml}$. 
Graded inocula of the live organisms, commencing with $0.25 \mathrm{ml}$. and increasing by $0.25 \mathrm{ml}$. until doses of $2 \mathrm{ml}$. were reached, were administered intravenously to rabbits at 3- to 4-day intervals. Fresh suspensions were prepared for each inoculation. When test samples showed satisfactory antibody response, the animals were bled out under general anaesthesia, the serum separated, phenol liquefactum added to give a final concentration of $0.5 \%(\mathrm{v} / \mathrm{v})$, and the antisera stored at $4^{\circ}$.

Bacterial extracts. Strains were grown for $24 \mathrm{hr}$. at $37^{\circ}$ on C.R.A. from which the rosolic acid had been omitted so that the dye would not tint the endproduct. Growth from a 4 in. Petri plate was scraped off and extracted according to the method of Fuller (1938).

Agglutination tests. Twofold dilutions of the antisera were set up. An equal volume of the appropriate suspension was added to each tube and results were read after $4 \mathrm{hr}$. incubation at $56^{\circ}$. The commencing dilution of each antiserum was $1 / 25$ and the highest dilution showing agglutination with complete clearing of the suspension was regarded as titre. Unabsorbed sera were used throughout.

Precipitation tests. The ring-test technique gave satisfactory readings and was employed in all tests. Readings were taken after $15 \mathrm{~min}$. at room temperature, using the sera used for the agglutination tests.

Absorption of precipitins. Formamide extracts were frozen and dried in vacuo over calcium chloride. The dried extract was added in aliquots to the antiserum at $30 \mathrm{~min}$. intervals until the desired absorption was achieved.

Organisms investigated. With the exception of Sh. sonnei strains which were isolated in this laboratory, all the organisms studied were obtained from the National Collection of Type Cultures. These are listed in Table 1 along with such information as was supplied with them.

\section{RESULTS}

Although the strains employed in this investigation were not identical with those employed by Gonzales \& Morales-Otero (1947), it was decided to follow the example of these investigators and arrange the agglutination and precipitation results with the Weil classification (Weil, Black \& Farsetta, 1944) as the base-line. This appears to be satisfactory. The remarkable specificity of the results in Table 2 suggests that eleven of the fifteen types have specific precipitinogens, and that, if agglutination occurs to titre with any of the antisera, it is more than probable that a positive precipitation reaction will also be obtained.

The similarities between the Flexner IV (103) and the Flexner Y strain and again between the Flexner V (P119) and the Flexner X, suggested that absorption of precipitins should be attempted. When done, it was found that each of these strains possessed a predominant precipitinogen (Table 3).

Further cultures were examined for their precipitinogen content against these fifteen antisera. They had been mainly classified in the past (Table 1) within the Andrewes \& Inman schema (1919), and as none of them gave 

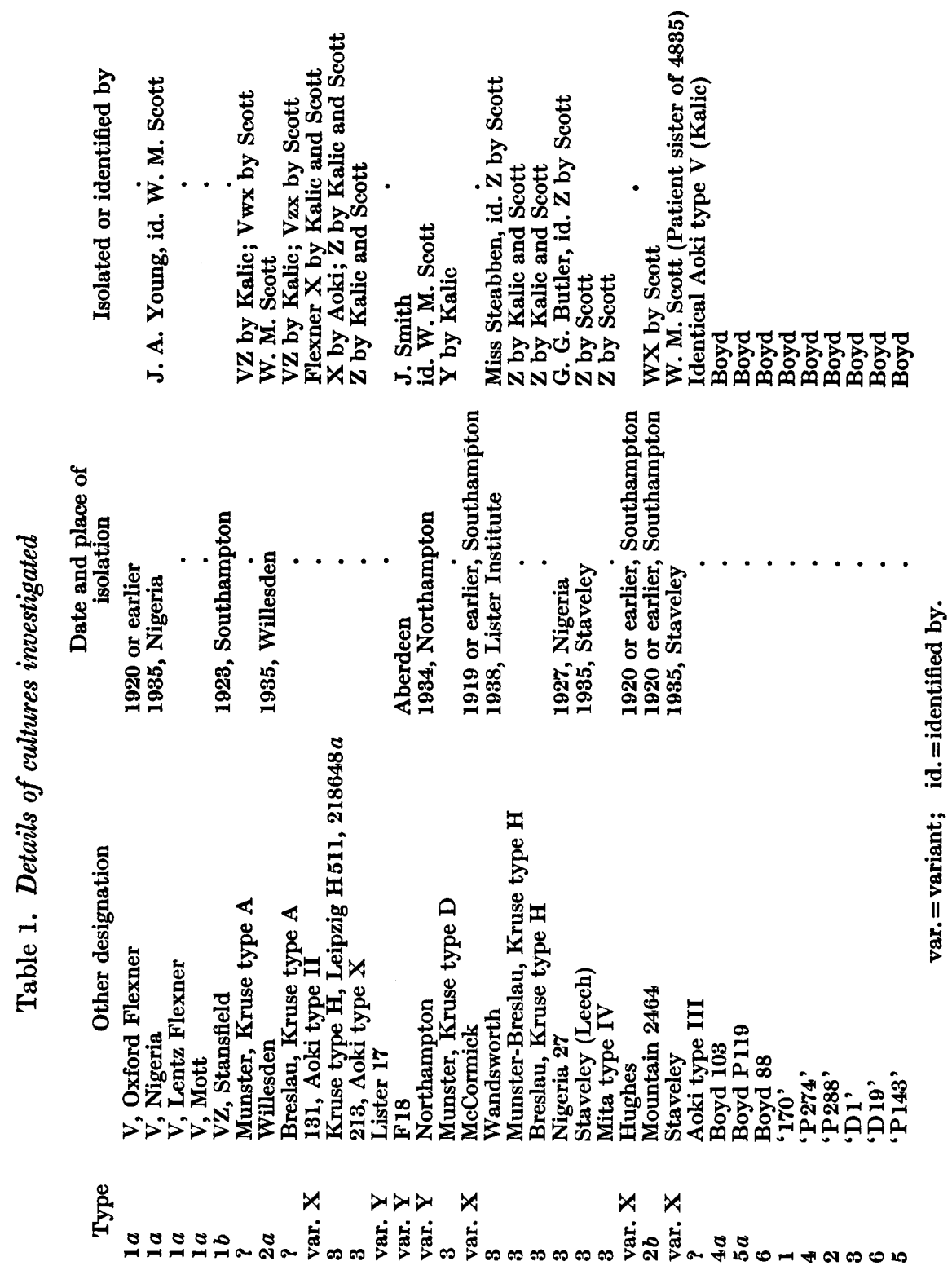

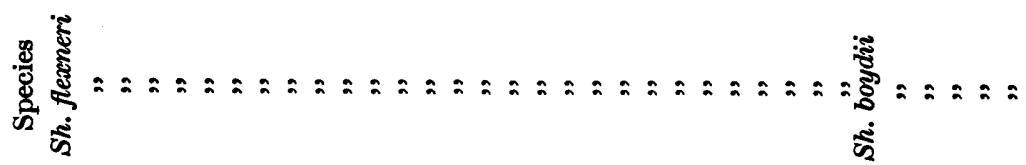

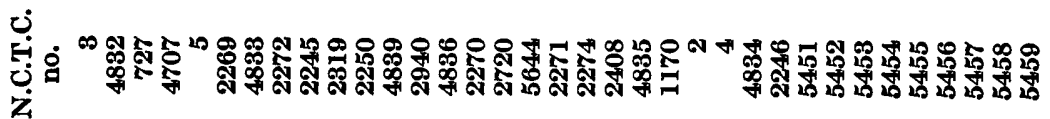


Table 2. Agglutination and precipitation results with selected strains of Shigella

$\begin{array}{ccc}\begin{array}{c}\text { N.C.T.C. } \\ \text { no. } \\ 3\end{array} & \begin{array}{c}\text { Other } \\ \text { designation }\end{array} & \begin{array}{c}\text { Weil } \\ \text { type }\end{array} \\ 4833 & \text { W } & \text { II } \\ 5644 & \text { Z } & \text { III } \\ 5451 & \text { Flex. 103 } & \text { IV } \\ 5452 & \text { Flex. P119 } & \text { V } \\ 5453 & \text { Flex. 88 } & \text { VI } \\ 2245 & \text { X } & \text { VII } \\ 4839 & \text { Y } & \text { VIII } \\ 5454 & \text { Boyd I, 170 } & \text { IX } \\ 5456 & \text { Boyd 2, P 288 } & \text { X } \\ 5457 & \text { Boyd 3, D 1 } & \text { XI } \\ 5458 & \text { Boyd 6, D 19 } & \text { XII } \\ 5459 & \text { Boyd 5, P 143 } & \text { XIII } \\ 5455 & \text { Boyd 4, P 274 } & \text { XIV } \\ & \text { Sonne } & \text { SIII }\end{array}$

(a) Agglutination

\section{Antigen}

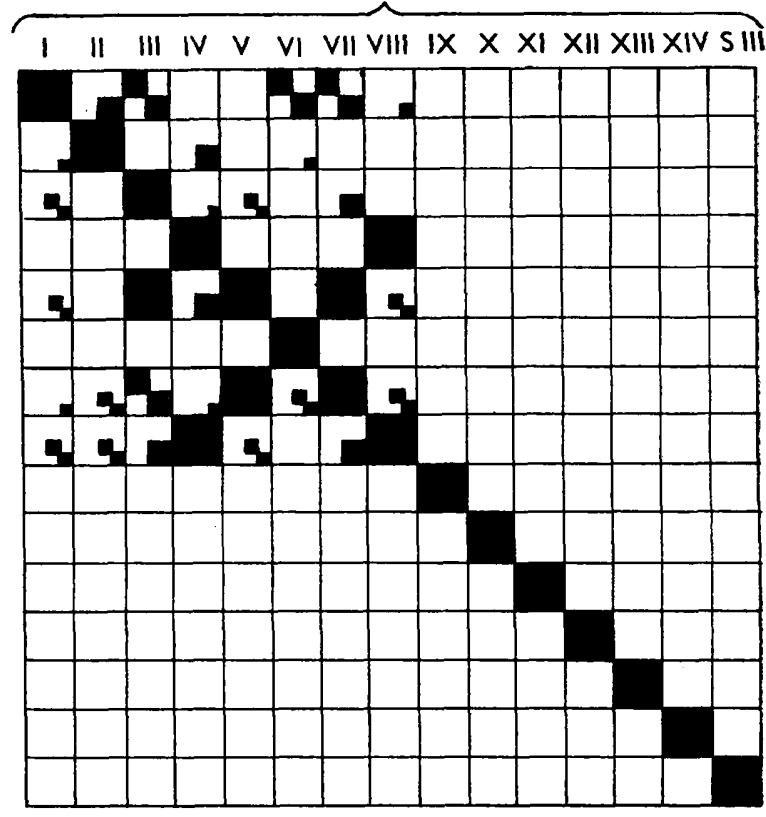

$$
\begin{aligned}
& 3 \quad V \quad 1+-\cdots---1 \\
& 4833 \text { W } \quad \text { II } \quad-+------- \\
& 5644 \quad z \quad \text { III } \quad--+------- \\
& 5451 \text { flex. } 103 \text { IV }---+--++--- \\
& 5452 \text { Flex. P } 119 \quad \vee \quad---++-+---- \\
& 5453 \text { Flex. } 88 \quad \text { VI } \quad-----+----- \\
& 2245 \quad \mathrm{X} \quad \text { VII }---+-+--- \\
& 4839 \text { Y } \quad \text { VIII }---+--+--
\end{aligned}
$$

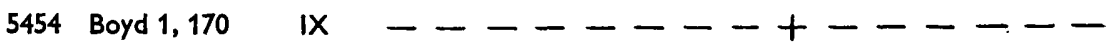

$$
\begin{aligned}
& 5456 \text { Boyd 2, P } 288 \quad \times \quad--------+--- \\
& 5457 \text { Boyd 3, D } 1 \quad X 1 \quad--------+-- \\
& 5458 \text { Boyd 6, D } 19 \text { XII }---------+-+- \\
& 5459 \text { Boyd 5, P } 143 \text { XIII }----------+ \\
& 5455 \text { Boyd 4, P } 274 \text { XIV }-----------+ \\
& \text { Sonne sIII }----------+
\end{aligned}
$$

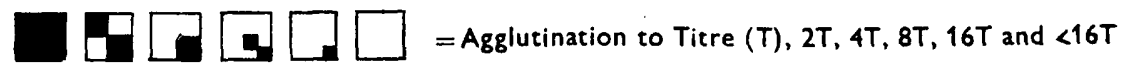

,$+-=$ positive and negative precipitation results. 
positive precipitation results with the Boyd types 1-6, agglutination tests were carried out with only the first eight of the fifteen antisera. The agglutination and precipitation results against these eight antisera are tabulated in Table 4.

The strains in Table 4 which gave positive precipitation results both with the Flexner V (P119) and the Flexner X antisera were tested with these sera after absorption of the $\mathrm{X}$ precipitin from the former and the $\mathbf{P} 119$ precipitin from the latter. The extracts now reacted only with the absorbed Flexner $\mathbf{X}$ antiserum, as shown in Table 5 .

Table 3. Results of absorption of precipitin experiments employing freeze-dried formamide extracts

\begin{tabular}{|c|c|c|c|c|c|}
\hline \multirow{2}{*}{\multicolumn{2}{|c|}{ Antisera }} & \\
\hline & & P119 & $\mathbf{x}$ & 103 & $\mathbf{Y}$ \\
\hline (1) & P119 unabsorbed & + & + & . & . \\
\hline (2) & P119 absorbed with $X$ extract & + & - & . & . \\
\hline (3) & $\begin{array}{l}\text { P119 as (2) further absorbed with P119 } \\
\text { extract }\end{array}$ & - & - & - & - \\
\hline (4) & $\mathbf{X}$ unabsorbed & + & + & . & . \\
\hline (5) & X absorbed with P119 extract & - & + & . & . \\
\hline (6) & $\mathbf{X}$ as (5) further absorbed with $\mathbf{X}$ extract & - & - & $\dot{.}$ & . \\
\hline$(7)$ & 103 unabsorbed & . & . & + & + \\
\hline (8) & 103 absorbed with $\mathrm{Y}$ extract & . & . & + & - \\
\hline (9) & 103 as (8) further absorbed with 103 extract & . & . & - & - \\
\hline (10) & Y unabsorbed & 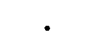 & . & + & + \\
\hline (11) & Y absorbed with 103 extract & . & . & - & + \\
\hline (12) & $\begin{array}{l}\mathrm{Y} \text { as (11) further absorbed with } \mathrm{Y} \text { extract } \\
\text { Controls }\end{array}$ & . & . & - & - \\
\hline (13) & P119 absorbed with V (N.C.T.C. 3 ) extract & + & + & . & . \\
\hline (14) & $\mathrm{X}$ absorbed with V (N.C.T.C. 3) extract & + & + & . & 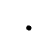 \\
\hline
\end{tabular}
,$+-=$ positive and negative precipitation results

The selection of ' $R$ ' and ' $S$ ' variants was confined to the Flexner and Sonne strains and the criteria laid down by Arkwright (1920-1) and Braun (1947) were applied. Only two strains - the Sonne type and Flexner W (N.C.T.C. 4833) - fully satisfied the requirements with regard to salt agglutinability, colony characters, and serological specificity. In both instances, extracts of the ' $R$ ' variants failed to give precipitation reactions with the antisera to the ' $S$ ' variants. None of the other strains, although rough in every sense except that of serological specificity by agglutination tests, completely lost their precipitinogens. Loss of specificity in the precipitation reactions was a frequent finding, cross-reactions developing which were absent with the corresponding ' $S$ ' strain. These results are similar to those obtained by Gonzales \& MoralesOtero (1947) with his so-called 'old strains'.

\section{DISCUSSION}

Seven of the fifteen 'smooth' strains selected as types in Table 2-N.C.T.C. 5453 (Boyd 88), N.C.T.C. 5454 (Boyd 170), N.C.T.C. 5456 (Boyd P288), N.C.T.C. 5457 (Boyd D1), N.C.T.C. 5458 (Boyd D 19), N.C.T.C. 5459 (Boyd 
Table 4. Agglutination and precipitation results with other strains of Sh. flexneri

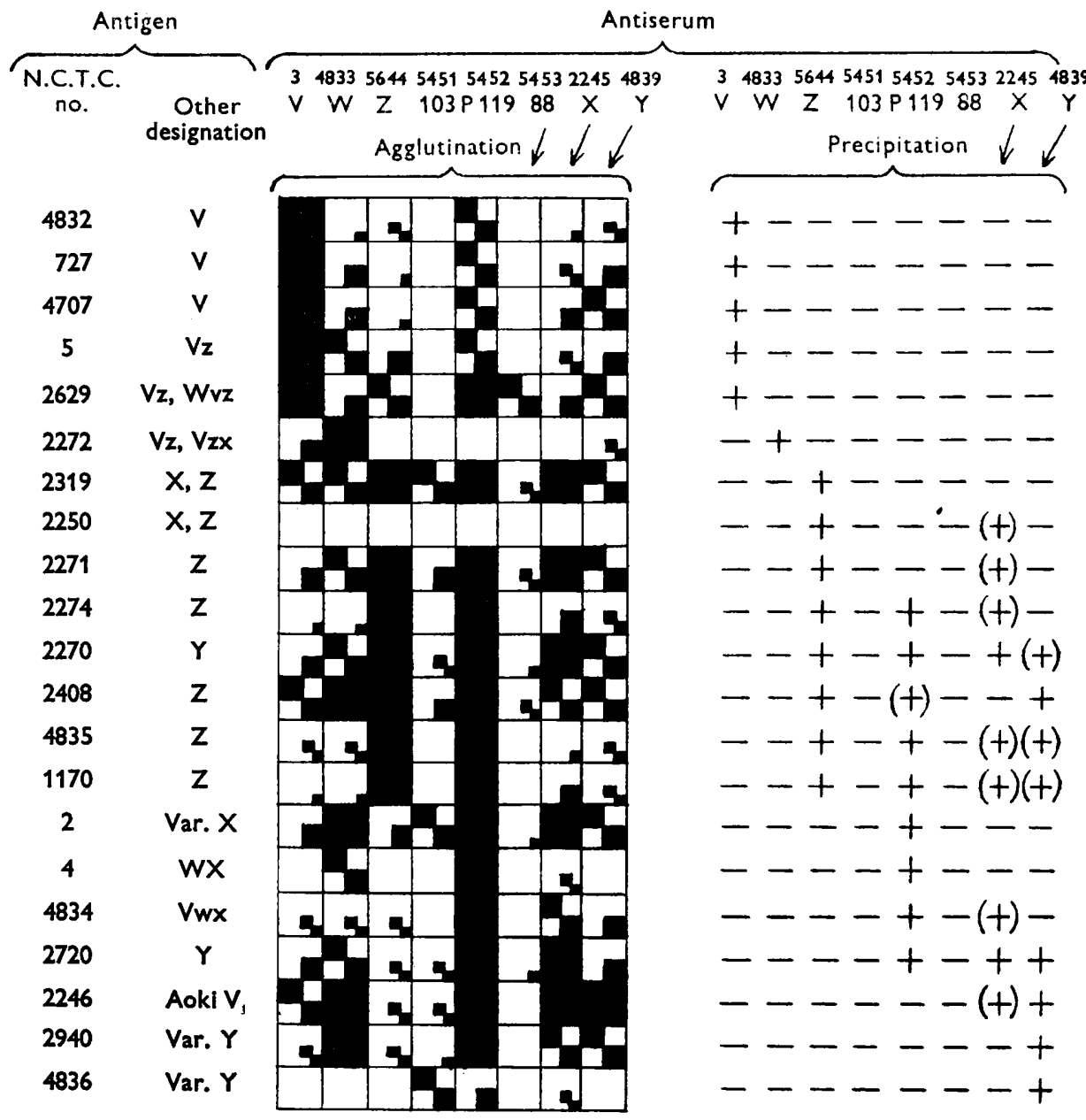

$\square \square \square \square \square \square=$ Agglutination to Titre (T), 2T, 4T, 8T, 16T and $\angle 16 \mathrm{~T}$

$+,(+),-=$ positive, trace positive and negative precipitation results.

Table 5. Analysis of strains in Table 4 showing cross-reactions with unabsorbed $P 119$ and $X$ antisera employing the same sera after absorption

\begin{tabular}{|c|c|c|c|c|c|}
\hline \multirow{2}{*}{\multicolumn{2}{|c|}{ Organisms }} & \multicolumn{4}{|c|}{ Antisera } \\
\hline & & \multirow[b]{2}{*}{$\begin{array}{c}\text { P119 } \\
\text { unabsorbed }\end{array}$} & \multirow[b]{2}{*}{$\underset{\text { unabsorbed }}{\mathbf{X}}$} & \multirow{2}{*}{$\begin{array}{c}\text { P119 } \\
\text { absorbed with } \\
\text { X extract }\end{array}$} & \multirow{2}{*}{$\begin{array}{c}\mathrm{X} \\
\text { absorbed wit } \\
\text { P119 extract }\end{array}$} \\
\hline $\begin{array}{c}\text { N.C.T.C. } \\
\text { no. }\end{array}$ & $\begin{array}{c}\text { Other } \\
\text { designation }\end{array}$ & & & & \\
\hline 2274 & $\mathbf{Z}$ & + & $(+)$ & - & $(+)$ \\
\hline 4835 & $\mathbf{Z}$ & + & $(+)$ & - & $(+)$ \\
\hline 1170 & $\mathbf{Z}$ & + & $(+)$ & - & $(+)$ \\
\hline 2270 & $\mathbf{Y}$ & + & + & - & + \\
\hline 2720 & $\mathbf{Y}$ & + & + & - & + \\
\hline 4834 & $\mathbf{v w x}$ & + & $(+)$ & - & $(+)$ \\
\hline
\end{tabular}

$+,(+),-=$ positive, trace positive, or negative precipitation results. 
P143) and N.C.T.C. 5455 (Boyd P274)-are specific to titre by agglutination and precipitation tests. The agglutination results are in agreement with Boyd (1938, 1940), and with Weil et al. (1944), and the precipitation results with Gonzales \& Morales-Otero (1947).

The specificity of N.C.T.C. 3 (Flexner V), N.C.T.C. 4833 (Flexner W) and N.C.T.C. 5644 (Flexner Z) by precipitation tests is complete, whereas Gonzales \& Morales-Otero (1947) found these organisms to give cross-reactions with Flexners $\mathbf{X}$ and $\mathbf{Y}$. Cross-agglutination reactions are marked as one would expect, since unabsorbed antisera only were used. Each organism agglutinates to titre with its homologous antiserum only, except the Flexner $\mathbf{Z}$ type which also agglutinates to titre with the Boyd P119 type antiserum. The Flexner Z type, therefore, does not bear out the other results, namely, that if agglutination to titre with any of the antisera occurs, a positive precipitation reaction with the same antisera may be expected. That this is indeed the case, is borne out by the results in Table 3 where other Flexner strains show the same peculiarity as the $\mathbf{Z}$ strain in Table $\mathbf{2}$.

In the past most controversy has centred around the Flexner $\mathbf{X}$ and $\mathbf{Y}$ types of Andrewes \& Inman (1919). These were not considered to be serologically distinct types and were omitted by Boyd $(1938,1940,1948)$ and by Wheeler (1944) in their classifications. By agglutination reactions Flexners $\mathrm{X}$ and $\mathrm{Y}$ are related to Boyd's types P119 and 103 respectively. Gonzales \& MoralesOtero (1947), from their precipitation investigations, agree with Boyd and Wheeler in discarding Flexners $\mathbf{X}$ and $\mathbf{Y}$, and with the former that they should be replaced by the Boyd types P119 and 103 respectively. Indeed, in Table 2, Boyd type P119 and the Flexner X type show very marked similarities both by agglutination and precipitation tests; the same similarities are evident with Boyd type 103 and Flexner Y. When, however, absorption of precipitins is carried out, it appears that each of these four organisms has a predominant precipitinogen. It seems that Boyd type P119 and Flexner X on the one hand, and Boyd type 103 and Flexner $\mathrm{Y}$ on the other, bear a relationship to each other in precipitinogen content similar to the balance of agglutinogens shown by Wilson \& Miles (1932) in smooth strains of Brucella melitensis and $\mathrm{Br}$. abortus. Using specially absorbed agglutinating antisera, Weil et al. (1944) found Boyd types P119 and 103 and Flexner types X and Y to be type-specific. Further evidence that this may be so is suggested by the two strains tested, N.C.T.C. 2940 and N.C.T.C. 4836 , both 'variant $Y$ ' types, which gave positive precipitation results with the Flexner $\mathbf{Y}$ type antiserum only (Table 4). That Flexner $X$ possesses a specific precipitinogen has been suggested above and appears to be substantiated by the results with absorbed sera (Table 5). Here certain Flexner strains-Z, Vwx and $Y$ (Kalic)-which show, among other results, cross-reactions with P119 and Flexner X antisera, react only with absorbed Flexner $X$ antiserum and not with absorbed P 119 antiserum. The cross-reactions noted in Table 4 are therefore due to the content of these organisms of X precipitinogen and not P119 precipitinogen.

The Sh. sonnei type strain employed was one isolated in this laboratory. The smooth variant is type-specific both by agglutination and precipitation 
tests. Numerous strains isolated here have behaved in an identical manner and none has given cross-precipitation reactions with the antisera available.

The behaviour of the ' $\mathrm{R}$ ' variants of $S h$. sonnei and the Flexner $\mathrm{W}$ strain (N.C.T.C. 4833) is in accord with Braun (1947), namely, that rough variants lose their precipitinogens. This has also been demonstrated in Sh. dysenteriae by Boroff (1949). Variants of the remaining Flexner strains which satisfied the criteria of roughness as defined by Arkwright (1920-1) retained their specific precipitinogen and developed non-specific precipitinogens.

It is essential for consistent results to grow the organisms on special selective media, such as C.R.A. (Brodie, 1942) to ensure a preponderance of smooth variants. Not only is this necessary in order to obtain specific precipitinogens but Takita (1937) showed that phasic variation in cultures of the dysentery bacilli also alters the agglutinogen content of these organisms.

This investigation deals only with the serological peculiarities of certain of the Shigella. The nutritional requirements of the same strains are being investigated in this laboratory by our colleague, W. Shepherd, whose findings will be published later. Classical Flexner strains and Sh. sonnei are much less exacting in their nutritional requirements than the Boyd types. The latter will not grow to any extent on any synthetic medium so far tested despite the addition of up to seventeen amino-acids and certain growth factors. It appears, therefore, that the Boyd types, as well as exhibiting a well-marked serological specificity, are also more specific in their nutritional requirements than the Flexner and Sonne strains. These findings may tend to add further weight to the proposals of Ewing (1949), who suggests that the Shigella, on the basis of serological and biochemical properties, be divided into groups A to E, $S h$. flexneri comprising group B, Sh. boydii group $\mathrm{C}$, and $S h$. sonnei and $S h$. dispar group D.

\section{CONCLUSIONS}

Among the dysentery bacilli studied and employing smooth variants, fifteen specific precipitinogens are demonstrated.

Boyd type P119 has its own predominant precipitinogen and a moiety of Flexner X precipitinogen; Flexner X possesses the $\mathbf{P} 119$ precipitinogen in minor amount and its own specific precipitinogen in major quantity.

Boyd type 103 and Flexner Y bear the same relationship to each other with regard to precipitinogen content as Boyd type P119 to Flexner X.

Precipitinogen and agglutinogen contents do not run in parallel.

'Roughening' produces varying degrees of loss of specificity of precipitinogen content.

Variation is of importance and can be overcome, in part at least, by employing special media favouring the growth of a particular phase.

The authors wish to thank Prof. Tulloch for facilities and criticism, Drs I. C. Whyte and $\mathrm{H}$. Williams for assistance in the early stages of this investigation, Dr W. Shepherd for permission to include data on nutritional requirements, and D. Gellatly for technical assistance. They also wish to thank Brig. J. S. K. Boyd for a subculture of his original D19 strain. 


\section{REFERENCES}

Andrewes, F. W. \& Inman, A. C. (1919). A study of the serological races of the Flexner group of dysentery bacilli. Spec. Rep. Ser. med. Res. Coun., Lond., no. 42.

Arkwright, J. A. (1920-1). Variation in bacteria in relation to agglutination both by salts and by specific serum. J. Path. Bact. 24, 36 .

Boroff, D. A. (1949). Study on toxin and antigen of Shigella dysenteriae. J. Bact. $57,617$.

Boyd, J. S. K. (1938). The antigenic structure of the mannitol fermenting group of dysentery bacilli. J. Hyg., Camb., 38, 477 .

Boyd, J. S. K. (1940). The laboratory diagnosis of bacillary dysentery. Trans. $R$. Soc. trop. Med. Hyg. 33, 553.

Boyd, J. S. K. (1948). The classification of dysentery bacilli. J. trop. Med. (Hyg.), 50-51, 169.

BraUn, W. (1947). A critical review of bacterial variation (with special reference to literature since 1935). Bact. Rev. 10-11.

Brodie, J. (1942). Modified Leifson media for the isolation of $B$. dysenteriae and pathogenic members of the colon-typhoid group. J. Path. Bact. 54, 499.

Brodie, J. (1948). Observations on the differential inhibition of coliform bacilli and rough variants of intestinal pathogens. J. gen. Microbiol. $2,1$.

Brodie, J. \& Shepherd, W. (1949). Further observations on the differential inhibition of coliform bacilli and rough variants of intestinal pathogens. J. gen. Microbiol. 3, 74.

Brodie, J. \& Shepherd, W. (1950). The effect of the gas-phase on differential inhibition of intestinal bacilli. J. gen. Microbiol. 4, 102.

Ewing, W. H. (1949). Shigella nomenclature. J. Bact. 57, 633.

Fuller, A. T. (1938). The formamide method for the extraction of polysaccharides from haemolytic streptococci. Brit. J. exp. Path. 19, 130.

Gonzales, L. M. \& Morales-Otero, P. (1947). Studies on the genus Shigella. Trans. R. Soc. trop. Med. Hyg. 41, 93.

MacConkey, A. T. (1908). Bile-salt media and their advantages in some bacteriological examinations. J. Hyg., Camb., 8, 322.

Takita, J. (1937). A new type of antigenic variation occurring in the Flexner group of dysentery bacilli. J. Hyg., Camb., 37, 271.

Weil, A. J., Black, J. \& Farsetta, K. (1944). The serological types of Shigella para dysenteriae. J. Immunol. 49, 321.

WheEler, K. M. (1944). Antigenic relationships of Shigella para dysenteriae. J. Immunol. 48, 87.

Wilson, G. S. \& Mrles, A. A. (1932). The serological differentiation of smooth strains of the Brucella group. Brit. J. exp. Path. 13, 1.

(Received 25 May 1951) 